\title{
Embodied Aging: Everyday Body Practices and Later Life Identities Among the South Asian Indian Gujarati Diaspora in Canada
}

\author{
Anusmita Devi \\ anusmita.devi@iitgn.ac.in \\ Indian Institute of Technology Gandhinagar \\ Tannistha Samanta \\ tannistha.samanta@flame.edu.in \\ FLAME University
}

Laura Hurd

laura.hurd@ubc.ca

The University of British Columbia, Vancouver

\begin{abstract}
This study explores how South Asian Indian Gujarati older adults in Canada (Greater Vancouver area) strive to maintain personal continuity, citizenship, and selfhood through everyday body management practices (exercise/yoga, medication/health supplements, skin, and hair care routines) and cultural markers such as food, sartorial choices, and community engagement. This examination, we contend, is noteworthy against the backdrop of contemporary North American academic and popular discourses of a burgeoning consumerist movement around the medicalization of bodies and anti-aging technologies. Drawing on in-depth qualitative interviews of 26 older adults, we discuss how growing old in the diaspora is marked with moral ambivalence between 'successful aging' and 'aging gracefully.' Based on an inductive thematic analysis, we identify four major themes in how the older diaspora negotiate aging and reorganise their lives through changing social relations and shifting cultural institutions. The first theme is the growing salience of both bodily and social changes in conceptualizing "old age," and how the experiences of aging vary by gender. Specifically, while most of the female participants visualized old age in terms of a loss of physical functionality, the male participants described agedness in terms of a loss of economic and social worth. The second major theme encapsulates the acceptable coping strategies for dealing with bodily changes and the associated reconfigurations of social roles. While a fit body and functionality were regarded as foundational traits for aging well by all participants, corrective measures or anti-aging products were not espoused as the most culturally appropriate "Indian" way of growing old. The third theme highlights the apprehensions regarding growing old in a foreign country, including a foreboding anxiety of dependence and frailty in the absence of traditional familial care networks. The final theme, explores how for most participants, the notion of home evoked ambivalence in constructing their sense of belonging and identity, often expressed through everyday practices and memory-keeping. Taken together, we ultimately show how age and embodiment are inextricably linked in the experience of growing old in the diaspora.
\end{abstract}

Keywords: Diaspora; embodied aging; body practices; later life identities; India

Anthropology \& Aging, Vol 42, No 2 (2021), pp. 86-104

ISSN 2374-2267 (online) DOI 10.5195/aa.2021.304 


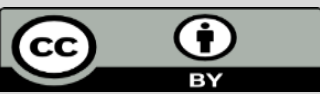

This work is licensed under a Creative Commons Attribution 4.0 International License.

This journal is published by the University Library System of the University of Pittsburgh as part of its

D-Scribe Digital Publishing Program, and is cosponsored by the University of Pittsburgh Press.

\title{
Embodied Aging: Everyday Body Practices and Later Life Identities Among the South Asian Indian Gujarati Diaspora in Canada
}

\author{
Anusmita Devi \\ anusmita.devi@iitgn.ac.in \\ Indian Institute of Technology Gandhinagar

\section{Tannistha Samanta} \\ tannistha.samanta@flame.edu.in \\ FLAME University
}

Laura Hurd

laura.hurd@ubc.ca

The University of British Columbia, Vancouver

\section{Introduction}

Led by the "successful" (Rowe and Kahn 1987) and "active" aging (United Nations 2002) paradigms, there has been a growing emphasis on individualism, positive affect, body image, and personal control over late-life outcomes in Western industrialized countries. The socio-political expectations around growing old have moved away from a framing of aging as a natural process of decline to a more medical, preventive paradigm, characterized by the belief in physical and cognitive plasticity. These ideologies share the assumption that not only is there a general potential to positively influence the aging process, but there is also an individual responsibility to do so (Davey and Glasgow 2006). The expectation to take responsibility for aging well through (bodily) self-control is stronger for women (Moore 2008). Research in Western industrialized countries has also demonstrated that femininity is inextricably linked to a youthful, healthy, and fit looking body (Carter 2016; Slevin 2006) and to a rejection of old age as an illness, that needs to be contained, controlled, and corrected (Bordo 1993; Brooks 2010; Furman 1997; Smirnova 2012). In contrast, growing old in India has often been culturally associated with an "appropriate dependence"1 (Lamb 2013, 172), reduced physical capabilities, and a socially expected withdrawal from pleasure, sociality, and material possessions (Lamb 2014). Lawrence Cohen, in his anthropological classic, No Aging in India: Alzheimer's, the Bad Family and Other Modern Things, argues that "old age in India is organized around an imminent 'problem of aging'- more old people and less desire and ability to take care of them... [such that] the language of gerontology (in India) is alarmist, often apocalyptic" (Cohen 1998, 89). While this sentiment dominated Indian gerontology for a considerable period of time (and still continues to govern questions of economic security and healthcare among aged), there is a slow and steady shift in the gerontological intellectual gaze (Lamb, 2000, 2013, 2014; Samanta 2018). Arguably, the neo-liberal market has slowly ushered in a 
new-age experience of growing old among the middle class in India where a consumption-based retirement lifestyle can be purchased without a loss of a productive and vital self. ${ }^{2}$

Taking into account these different forms of understanding aging and their merging through globalization we examine the resultant cultural tensions in aging by looking at the social experience of growing old among the South Asian Indian Gujarati diaspora in Canada. We attempt to understand how older adults in the diaspora navigate rapidly shifting realities of globalization and the multiple imaginations of home and feeling of nostalgia as they strive to maintain personal continuity, identity, and selfhood through everyday practices. To accomplish this, we address three interrelated research questions on the embodied experience of growing old in the diaspora. Our use of the term embodiment draws on the post-structural, phenomenological approach that allows one to make and remake their bodies through routinization of practices (Csordas 1999; Turner 1995). First, we ask how does the older South Asian Indian Gujarati diaspora perceive and experience aging? Second, what coping mechanisms do they employ to navigate changes in later life? Finally, how are later life identities shaped and reshaped in a transnational context? In what follows, we mine the sociological and gerontological scholarship (both theoretical and empirical) on the intersections of the body, consumerism, and aging whilst also paying attention to the literature on diaspora.

\section{Literature Review}

While aging, in general, is seen as a degenerative process leading to loss of physical vitality and cognitive abilities, this perspective on aging is especially damaging for women. Women's worth is inevitably related to their appearances, specifically their ability to embody youthful beauty ideals (Sontag 1972; Wolf 1991). "Being physically attractive," Susan Sontag (1972) asserts, "counts more in a woman's life than in a man's, but beauty, identified, as it is for women, with youthfulness, does not stand up well to age" (31). The "bio-medicalization of aging" (Estes and Binney 1989) and the cosmeceutical lens have further demonized the aging body; now, aging is perceived as a pathological condition, a disease that needs to be managed, or a problem that needs to be solved (Clarke et al. 2003; Conard 2007; Katz 1996). In a similar vein, anthropologist Susan Greenhalgh (2015) highlights the emphasis that American society places on containing and correcting fat bodies, a phenomenon which equally reflects how the social responsibility of becoming good biocitizens rests singularly on individuals. Michelle Hannah Smironova (2012) in her content and discourse analysis of magazine advertisements in the United States, argues that cosmeceuticals are positioned as drugs which assist with the curing, containing, or modifying of the disease of aging. She further asserts that the success of the cosmeceutical turn in the anti-aging enterprise is brought about by the increasing commodification of medicine coupled with the medical "life-extension project," which she defines as a "combination of technologies, knowledges, and practices directed at the aging body which seek to prolong life through all available means (based on self-surveillance and preventative behaviours), and the consumption fields of cosmetic surgery" (1237).

More generally, studies show how science, medicine, and consumer culture negotiate 'acceptable' appearances of aging through the prescription of various regimens of aesthetic maintenance (Bayer 2005) for the aging woman. Aging woman is portrayed to be able to recuperate an acceptable identity only through particular modes of consumption (Davis 1995; Holstein 2006; Hurd Clarke 2011). In a renewed interrogation of the "cultural turn," Julia Twigg and Wendy Martin (2015) contend that the body have become the key sites for the operation of new kinds of "governmentality" (Foucault 1991). Older bodies are increasingly subjected to disciplining by various regimes of fitness and health (Slevin 2008; Slevin and Mowery 2012). It is worth noting that while women's bodies are more likely to be subject to social surveillance, men's bodies and social roles in later life have received marginal attention 
in gender scholarship. While there is no denying that the majority of men in most societies benefit from institutionalized forms of patriarchal privilege, the heterogeneity of that experience is worth investigating. As such, masculinity studies informed by critical theory note how gender practices and age relations form critical axes of inequality where the social category of male seniors are collectively viewed as degendered or genderless (Thompson, Jr 2019). This, in turn, homogenizes the vast differences among mature men and blurs older men's distinctive and varied subjectivities.

Appearance, as noted above, is an important dimension of embodiment, specifically for the performance of age, gender, and identity (Calasanti and Slevin 2001; Furman, 1997). Older women are expected to engage in numerous forms of beauty work such as the use of hair dye, dieting, exercise, make-up, and non-surgical and surgical procedures in order to approximate youthful body ideals and arrest agedness (Furman 1997; Hurd Clarke and Korotchenko 2010). While some scholars such as Sandra L. Bartky (1997) view engagement in such practices as unquestioned submission to the patriarchal demands on the body, others have suggested that body practices may not always be oppressive but rather may be integral to building older women's self-esteem and identity and fighting body dissatisfaction in later life (Carter 2016; see also Bordo 1995; Fraser 2003; Gange and McGaughey 2002; Heywood and Drake 1997). Susan Bordo (1995), for example, sees body correction as a means by which individuals may reclaim control over their bodies and their embodied selves.

\section{Aging across cultures: Social roles and identity formation among older immigrants}

Several studies have explored age-related changes in social roles and values in a variety of cultural contexts. For instance, in their recent study of rural Tanzanian older women, Sylivia Karen Rutagumirwa and Ajay Bailey (2017) found that aging led to a shift in familial responsibilities and status. Tae-Ock Kauh (1999) found that older Korean American adults in Philadelphia experienced a loss of social status and power in their families. The participants in Sabrina T Wong, ${ }^{1}$ Grace I Yoo and Anita L Stewart (2006) study of older Chinese and Korean immigrants in the United States reported feelings of both concern and relief with their participants, as they became peripheral members of the family, lost familial authority, and became more independent as they aged.

In her discussion of aging Baby Boomers, Naomi Woodspring (2016) argues that social identities are carefully crafted through adaptations in appearance, roles, and health. Likewise, Margaret Gullette (1997) discounts the idea of a core, singular, master identity and espouses the possibility of multiple, shifting identities that are contingent upon cultural beliefs, values, and practices. She places age in the centre of the social construction of identity. Sociologist Richard Jenkins offers yet another useful conceptual entry point in understanding the contestations around the idea of identity. Jenkins (2010) furthers the theory of multiple, integrated, relational identities by making embodiment the focal point of analysis. In fact, in his later analysis, social identity is considered as a "process-identification-not a thing" (Jenkins 2010, 5), opening up the avenue to explore the continuous process of negotiations through which identities are shaped and reshaped in later life. Noteworthy in this regard is the work of Finnish sociologist, Lena Nare (2017), who points out that the Gujaratis who live in North London still continue to have ties with not only India but also with the East African nations of Tanzania, Kenya, and Uganda, countries from which they had emigrated to the UK. Nare observes how 'home' often holds ambivalent references to multiple geographic sites. For example, for Nare's partcipant, the idea of home encompassed the everydayness lived in North London interspersed with the occasional escapes to extended family or to nostalgic memories of a childhood spent in India and/or East Africa.

Finally, although there is a growing body of gerontological scholarship in South Asia, discussion of the crucial link between culture and aging is often neglected. While the aging mind has received some 
attention through the articulations of cultural anthropologists (see for example, Brijnath 2014 and Cohen 1998), few studies have considered the cultural construction of aging bodies in the Indian context (exceptions include Lamb 2000, 2002a, 2002b, 2014; Samanta 2018). It is this lack that we seek to address by drawing attention to the salience of the body and everyday body practices in shaping the understanding of old age and later life identities in a transnational context.

\section{Conceptual Framework: Body Practices and Embodiment}

We adopt a post-structural and cultural gerontological lens to understand the interconnected notions of body and identity in later life. In the poststructuralist school of thought, the body is seen as transcending its natural or biological existence and categorization to give way to culturally inscribed meanings and identities (Alcoff 1988; Bartky 1997; Butler 2004; Foucault 1978). The body is thereby considered both a product as well as an agent; both the embodied subject and the culture are produced, sustained, reproduced and changed simultaneously through dynamic social interactions. Feminist poststructuralists often focus on everyday body practices and their relation to subjectivity, performativity, and the disciplinary demands of normative femininity.

Sociological scholarship concerning the body culture and body image have primarily focused on the younger population (particularly, younger and middle-aged women), while a growing yet still relatively limited number of studies have considered aging bodies. The recent cultural turn in gerontology (Gilleard and Higgs 2005; Twigg and Martin 2015) has brought the body and embodiment to the forefront in gerontological discourses. Julia Twigg and Wendy Martin (2015) suggest that developments in cultural gerontology have re-emphasised and reconfigured the meanings associated with aging. With its emphasis on agency, lived experiences, and the individuality of older adults, cultural gerontology has reconceptualised identities as plastic with the possibility of being made and remade through life choices, values, judgements, and discourses. Seen this way, a cultural gerontological framework privileges the relational aspects of later life identities and the embodied ${ }^{3}$ experience of aging. For example, while arguing how clothing is age-ordered, Julia Twigg (2018) shows that the choice and presentation of clothing have a mediating, performative dimension thus bringing bodies, clothing, and culture together.

Our post-structural understanding of the socialized body allows us to appreciate the social construction of the disciplinary gaze (Foucault 1979) where the individual becomes her/his own agent of surveillance and conforms to the normative constraints of the lived context. We do this by analyzing everyday body management practices (e.g., exercise, yoga, diet, medication/health supplements, and skin and hair care routines) as well as identity-making cultural markers (e.g., food and sartorial choices, social interactions, and community engagement) among older Indians in the diaspora.

\section{Method and Data}

The study was supported by a doctoral fellowship from the Shastri-Indo Canadian Institute (2017-2018) awarded to the first author. Ethical approval was obtained from the Ethics Review Boards of both Indian Institute of Technology, Gandhinagar and the University of British Columbia.

\section{Study design}

Between August and November 2017, 26 older adults aged 55 years and above (13 males and 13 females) were interviewed by the first author. The participants were recruited using snowball sampling methods and with the help of a gatekeeper who was a well-connected member of the Gujarati immigrant community in the Greater Vancouver region where most of the Indian immigrants in British Columbia reside. The semi-structured interviews explored the meanings that people assigned to old age and the 
strategies they adopted to cope with the age-related physical and social changes. As such, participants were asked whether they considered themselves old and about their perceptions and apprehensions regarding aging and the physiological and social changes they observed over time. Interviews lasted between 40 minutes to 3 hours and were conducted in a variety of locations, including public places like restaurants and parks as well as respondents' homes and workplaces. Twenty interviews were tape recorded while six interviews, where the participants expressed reservations about recording the interview, were noted down by the interviewer. All of them used a combination of English, Hindi, and Gujarati to communicate with the first author. The Gujarati and Hindi portions of the interviews were translated after transcribing the audios verbatim. The first author took field notes about her observations of the surroundings and the body language of the participants, which were used to build further insights into the narratives.

\section{Study participants}

All the participants were of Gujarati Hindu origin and had been living in Canada for ten years or more. ${ }^{4}$ They had a varied migration history ${ }^{5}: 10$ were former political refugees who had migrated in the early 1970s to escape the political unrest in African, 12 were first-generation labor migrants, and 4 were 'zero generation' migrants who had followed their migrant children in later life. Although a sociological categorization of class (especially, the Indian middle class) remains conceptually contested and empirically ambiguous (see for example, Fernandes 2006; Mazzarella 20116), for the purpose of our study, we defined social class positions based on visible economic markers such as property and car ownership, (independent) living arrangements, and socio-cultural distinctions such as English language proficiency, club memberships, social networks, and finally, self-perceptions of their social class. By this classification, all our respondents belonged to the middle class. All but one female participant, who had moved to a rental apartment following her husband's death, owned their own houses. With the exception of six participants who lived with their adult children, one woman who lived with her mother as she was the sole care provider, and one man whose parents co-resided with his family, the majority of them either lived alone or with their spouses. Table 1 presents descriptive information about the sample.

Table 1: Descriptive characteristics of South Asian Indian participants $(\mathrm{n}=26)$

\begin{tabular}{|l|l|}
\hline Age(years) & N \\
\hline $55-64$ & 9 \\
\hline $65-74$ & 13 \\
\hline $75-84$ & 4 \\
\hline Place of birth (continent) & \\
\hline Africa & 10 \\
\hline Asia & 15 \\
\hline North America & 1 \\
\hline Marital status & \\
\hline Married & 23 \\
\hline Separated & 1 \\
\hline Widowed & 2 \\
\hline Living arrangement & \\
\hline Alone & 1 \\
\hline With spouse only & 13 \\
\hline With children/parents & 12 \\
\hline Migration type & \\
\hline
\end{tabular}




\begin{tabular}{|l|l|}
\hline Twice removed & 9 \\
\hline First generation & 11 \\
\hline Zero generation & 5 \\
\hline Second generation & 1 \\
\hline
\end{tabular}

\section{Analysis}

The data were analyzed thematically following previous work on reflexive thematic analysis in qualitative research (see Braun \& Clarke 2006; Terry, Hayfield, Clarke \& Braun 2017). After reading through the texts of all interview transcripts, tentative categories were assigned by the first author to perceptions and narratives of the participants. These categories helped in identifying common themes that emerged from the narratives. The themes were decided in consultation with her third author, Dr. Samanta, who also re-read the transcribed interview material. Our analysis resulted in four overlapping themes which highlight how older adults perceive, experience, and cope with their aging bodies and how they negotiate their identities in later life through everyday practices. All names have been changed to protect the privacy of the participants.

\section{Changing bodies, changing roles: Gendered associations}

Most of the participants, described old age in terms of changes to their physical bodies and social roles. They primarily used two parameters to map these changes in their bodies, namely physical appearance and functionality. While most of them expressed a sense of loss because of corporeal changes (e.g., loss of thicker hair and slimmer body), they also conveyed feelings of resigned acceptance to these bodily changes. For instance, Nirmala (65), who had immigrated to Canada post-marriage, said that though she was not happy with her weight gain and thinning hair, it was important to accept these inevitable changes:

... Obviously you are not as young as you were ten years back. . When I was 55, I think I was more athletic. Now ... sometimes I really feel that pain can do that much damage .. . So, then I said, "oh wow! maybe I am aging." And then obviously your body structure changes as well after a certain age. As I said, if I would have kept up walking and my own exercises it wouldn't have bothered me. But yes, it does now ... Yeah you get a little slow, slow in work ... You lose your hair so naturally I notice that it's getting thinner. I used to have very thick hair and obviously it got a little lighter here so I said, "Wow it shows" ... (But) I should always love myself no matter what, it's still me right!"

Another common vector that emerged during discussions about the meaning of old age was the experience of compromised body functionality. Echoing the sentiments of many respondents, Sangeeta (65), born and raised in Canada, shared:

I am aging, that's for sure. I can't refute that. It is happening. . . I am 65, but I won't say I am old. I am still able to function, you know. When I reach certain age and all these things slow down and when I can't look after my self, do my own things myself. . . that will be old. I don't know when that will happen. I hope not too soon.

Although Sangeeta acknowledged changes in her body, she did not feel she was old yet because for her, old age would mean diminished body functionality. 
Unsurprisingly, while most of our female respondents described old age in terms of their bodily changes, most of the older males defined aging in terms of changes in their professional and/or social roles. For instance, Dilip (82) reported how his social roles had changed over the years. While he had remained actively engaged in his family business in Canada until a couple of years ago, he lamented how age had slowed him down:

Well, it (role) has changed in last 5 years. . . Change in role includes, when I started getting older, I gave almost everything to my son, like my savings, the house. . He was really young when I bought this house. Now I have added his name (to the ownership document) ... If we both (he and his wife) pass away, then he should not face any legal or accounting problems.

Articulating the sense that his social value had diminished, Dilip expressed his discontent with his changed role and status in his social circle:

... When younger boys (men) come (to social gatherings) they get honoured. I have grown old now, so no one even wants to talk to me. . . people will just come and say "hello/ hi" and nothing much. . . before they used to discuss. . "we have to do this, we have to do that" . . . because I was in a voluntary society for almost 15 years. Now no one discusses with me.

A majority of the participants (20 out of 26) expressed unhappiness at the prospect of changed social roles and status with advancing age. While five men and women expressed that they enjoyed the reduced social responsibilities, one older woman felt there had been no change in her social role with age. Sushma (77), who resided with her extended family (spouse, adult son, daughter-in-law, and grandchildren), felt that she had more time for herself after her parental and grandparental responsibilities eased with age. She mused:

Growing old, no change as such. Everything is like before. . Now I do not work that much. My daughter-in-law helps more in the kitchen. She comes home early, and we cook dinner together... Also grandchildren are all out (in college) so not much work is there. . I like it. I can nap in the afternoon. . . Earlier, I would be busy with chores. . .

The interview excerpts above reflect the participants' feelings of ambivalence about the inevitability of age-related physical and social changes. While a yearning to hold on to the permanence of an enduring lifestyle and life-status was the common refrain, there were also exceptions undergirding the heterogeneity and hybridity (Lowe 2005) of the diasporic experience.

\section{Repurposing age: Everyday body practices}

Akin to earlier studies on aging and the body (Bennett et al., 2017; Hurd Clarke 2002a), participants in this study reported a reprioritization of bodily attributes. For instance, on being asked about any physiological attribute that he would like to change, Mohan (65) noted:

M: I do not want to change anything about my body. . Nothing. I am happy the way I look. . . maybe the knees. Yes, the knees; if I could, I would like to get new knees. Not replaced, artificial but you know, like when I was younger, without pain and all. I could move around.

AD: So, what would you like to change (about your appearance or body)? 
P: Get some more energy yeah; that's it.

Use of body management practices such as following a diet and exercise schedule to arrest the somatic expression of aging has been widely reported in several studies (Laz 2003; Slevin 2010). Our participants too, described efforts to manage their changing bodies through dietary changes, exercise and yoga regimes, and medications and health supplements. For instance, Vanadana (74), who had migrated from Tanzania in the 1970s, emphasized a positive association between fitness in later life and maintaining an active lifestyle:

I am 74 years old. I still go to work. I also take care of the house. . I go for walks during my lunch break and also attend yoga classes three days a week. . Do not stop working if you want to stay fit.

She further mentioned that several other activities, such as taking public transit to work, looking after her grandchildren, and regularly driving to religious gatherings all formed an integral part of her active lifestyle.

Many male interlocutors also reported taking active care of their health with increasing age. For instance, Nitin (64) took health supplements and carefully monitored his health status. He said:

(I take) Only supplements. . As you get old you take 50+ one pill a day supplements or vitamins, proteins, and etc. We (he and his wife) are just careful with food. I mean we do have regular check ups at the doctors about our heart rate and blood sugar, cholesterol level and weight.

At the same time, unaffected by the popular media propagation of beauty and body products, most of the older adults reported refraining from using any anti-aging topical products or surgical/non-surgical corrective measures. This finding aligns with earlier findings on Indian diaspora (Sarah Lamb et al. 2018). The cultural belief in maintaining the sanctity of the body often influenced the age-managing measures adopted by them. Several participants subscribed to the idea of aging 'gracefully' or 'naturally' as opposed to adopting invasive, age-corrective, clinical or surgical methods. For instance, Vinita (62), who had migrated from East Africa in the 1970s after her marriage, expressed her lack of trust in pharmaceutical products and a preference to age "gracefully" - a term commonly invoked by most of the older men and women. With her formal training in chemistry, she said that she had "scientific" reasons for not believing in the efficacy of these anti-aging products. She noted emphatically the following:

I do not believe in it (anti-aging products). What pharmacies do is sell products. But I don't know, after certain years what's going to happen. If they are not taking either that medication or injecting themselves, what could happen. It could be worse than natural aging. So, I don't like to do those things. I would rather age gracefully than do those things.

\section{Growing old in a foreign land: Dependence, isolation, and loneliness}

The biggest source of anxiety reported by the older adults was increased dependence with age. Preeti (56) illustrated this "dependence anxiety"7 (Vatuk 1990, 65). She had migrated from India after her marriage, and, at the time of the interview, both she and her husband were working professionals in 
Canada. She described herself as independent and ambitious since childhood and expressed her fears about becoming dependent in the future, especially for household chores:

The only apprehension I have about growing old is having to depend on someone else. .. I go to Vaishno Devi ${ }^{8}$ (temple) every time I visit India. I ask my friends to join but they always have excuses: "Who is going to look after the house?; I can't leave the family unattended" and all. .. We are more independent here.

For the eight women and two men who did not stay with an extended family, the prospect of becoming unable to take care of everyday household chores such as cooking and cleaning, was a major concern. Even among older adults who resided with extended family, especially females, expressed concern about their inability to help with household chores/grandparental duties with age and increased dependency on younger family members. For instance, Sangeeta (70), a zero-generation migrant, resided with her extended family. She enthusiastically mentioned that she kept herself busy with domestic chores and grandparental duties and did not like to sit idle. She said:

I fear that I might not be able to help around in the house later. . grand kids are there. They will grow up. But in the kitchen, there is work. I love cooking for the family. I make a lot of Gujarati snacks and fritters even now. I don't sit idle at all.

Four older women, Nirmala (64), Sushma (78), Sangeeta (70) and Mitushi (70)], two first generation migrants and two zero-generation migrants, respectively, drew a comparison of the ease of taking care of household work in India because of availability of cheaper labour and joint living arrangement. For instance, Mitushi, who had migrated from India after the birth of her grandson, said with a heavy heart:

It was easier there. . . A servant (domestic help) used to come everyday. I also had my elder sister-in-law (husband's brother's wife). We used to get things done together. . . Sometime after coming here I developed cancer, she helped (daughter in law), but she has her work. She still helps in the kitchen. . but. . .

While the older females were mostly concerned with the inability to take care of domestic chores, most of the older men expressed a fear of increased dependency on others for taking care of their bodies and mobility or loss of cognitive capabilities. For instance, Jethalal (65) and Manohar (70) both feared the possibility of developing dementia in later life. Jayesh (55) and Bhagwan (69), both living with extended family, feared that they will not be able to take care of their bodies with old age and will have to depend on others for meeting their daily needs.

Interestingly, though most of the participants were anxious about the increasing dependency with age amidst the absence of strong familial support, long term institutionalization did not seem to be a widely chosen option for later life care. Only a single female brought up institutionalized care facilities during her interview. Her deceased husband had been put in a care facility, and she was not keen on finding her way into one. The rest of the twenty-five participants did not discuss the idea of assisted living as an option for later life support. At the same time, all the twenty-six older men and women mentioned that they were happy with the Canadian health care system, old age pension plan, and the transportation service for older people with mobility restrictions.

Several participants also reported feeling lonelier with increasing age, especially after retirement. This feeling of loneliness, they believed, was more profoundly felt when being in Canada than in India. For 
instance, Dilip (82), who loved traveling, but rarely did so anymore as he preferred not to do it alone, had this to say:

If I go to India, I have lots of friends and relatives. So, it is not a problem. Somebody will come and pick me up. If not, then I can go by taxi and go to their house. So, we are with the family. So, there is not a problem. But here if I have to go somewhere, then I have to stay in a hotel, then I would like to have somebody. . . Because there is a fear if something happens, something goes wrong, you know health wise. Though there is insurance and everything, and you cannot maneuver yourself. Like you know, if I have to order a taxi, or kaha khana khane jayenge (where would I go for lunch/dinner), you know, to look for a restaurant and all these things, that information is there but still I feel alone, lonely.

Like all the others in this study, Dilip too had great faith in the Canadian healthcare system. He had narrated an incident where he believed a critically ill acquaintance of his in Canada could not have been saved had he been in India. However, with increasing age, as evident in the excerpt above, he felt the need to be with familiar people in case of medical emergency to call for help and take care of initial official procedures. This reflects the tension that most of the respondents felt in navigating old age in Canada. While they praised the government health care system, they also lamented the scarcity of readily available familial support to take care of them in case of medical emergency (which was believed to be available in India because of stronger network ties).

Twenty participants made comments similar to that of Sangeeta (65), who described loneliness as an important concern for older persons in the diaspora, in the absence of strong familial support and limited social interaction with the larger community:

The only. . . bad thing is, there is tremendous loneliness here. When people get into their senior ages, children are gone, they are doing their own thing, and nobody comes to visit them. . . In the last years of their lives, they need loving, caring people to look after them, to be there, to listen to them. Their last memories and experiences that they want to relate. Nobody is there to listen to them. . . Whether it is true in India or no, I don't know. But here that is the biggest hurdle.

Interestingly, not linguistic barrier ${ }^{9}$ but weather was cited as a major cause in restricting social interactions. Several older adults commented that the harsh winter and incessant rains in Vancouver affected their social participation. Distance also emerged as a deciding factor in fostering social interactions. Since the Gujarati community in the Vancouver area was scattered, often, most of the them had to travel some distance to attend community events. Six participants reported inability to drive (two had medical conditions; four did not own a car, did not know how to drive, and relied on public transport or their children for commuting). Five of them stated that distance was a limiting factor for social interaction since they had to travel to meet people of their community. Three other older men who had access to vehicles and could drive around also mentioned that their social interactions had reduced with increasing age because they started finding it difficult to drive long distances to attend community gatherings and events. Two older women were enrolled in community centres/support groups for older adults and did not report feeling lonely. One of them, a zero-generation migrant (had no language barrier), interacted only with fellow Indians at the old age centre, while the other participant, a first-generation migrant, had friends of Canadian as well as Indian origin. One older woman who was actively involved in a spiritual organization, did not report feeling lonely either since she mentioned being "busy with office work" throughout the day. Additionally, two older men and one 
older woman, who lived in a joint household setup with young grandchildren did not mention feeling lonely.

In the face of these age-related apprehensions and fears, many participants stressed the importance of acceptance and preparedness. For instance, ten years ago after her husband in India passed away, Nirupa (64) migrated to Canada to be close to her only son. She lived in an apartment close to her son's house and spent several hours every day at a seniors' centre where she enjoyed spending time with other women. Although there were non-Indian older persons in the centre as well, Nirupa's group of friends comprised only of Indian older females, mostly Punjabi speaking. She liked coming to the centre not only for socialization and recreation but also because of the informative sessions on nutrition, exercise, and yoga for seniors by trained professionals, which could prepare her for physiological changes that accompanied aging. Nirupa noted:

I have had really bad knee pain and ... felt like okay I have to look after this, I have to get it back on track that was my thought... fears are just another way of telling yourself to make sure that you have made arrangements for yourself ... I joined this centre because of a Punjabi lady near my house. She comes here too. She told me about the activities here ... We have restorative yoga classes ... medical experts come once a week to talk about handling things, you know, like fall, and pain.

\section{Fitting into two worlds: The quest to belong}

In this final theme, we examine our participants' everyday dilemmas of negotiating nostalgia, identity, and the sense of belonging. This is significant since the social process of growing old reflects the intersections of micro-processes and macro-level forces of individual aging experiences (Estes, Biggs, and Philipson 2003). In our study, many older adults reported that with reduced familial and professional (post retirement) responsibilities, they had time to travel. This, coupled with the Canadian winters, and reportedly reduced physiological abilities to cope with it (with advancing age), encouraged many of them to spend time in India from October-November through February-March to escape the biting cold. This resultant seasonal migratory pattern is not new in gerontological scholarship. ${ }^{10}$ Several respondents mentioned that they owned residential properties in their "native place" (often in Gujarat, India) which served as retreat homes as well as routes to forge local social ties. For instance, Manohar (70) had bought a house in his hometown:

(I go) every year because it's cold (in Canada) and when you come back it would be nice again. So that's the main thing. As soon as I returned (after retirement), we built a very nice house ... it is not big and in the heart of city. It takes five minutes, rickshaw take five minutes to take us from my place to city. So, we built the house and this house like all bedrooms has attached bathroom and toilet seat. Nice yard in the back. So, we'd like to relax there.

Several gerontological scholars have noted that memory is an integral part of constructing identities (Hoods 2011; Jenkins 1996; Woodspring 2016). Indeed, many of ourrespondents described how their memories of embodied experiences in both cultural contexts shaped their later life identities. For instance, 64-year-old Hiral, while talking about her dietary preferences, shared that her preference for "Canadian" food over "Indian" food was influenced by racial prejudices that she had faced in public and professional spaces during her younger days. Hiral recounted how a racially, discriminatory public environment led her to feel pressured to learn English, acquire professional culinary skills, and take up work at a Canadian restaurant. She said that the fear of smothering her clothes with the smell of garlic 
and other spices with strong aroma(often used in Indian cooking), which at times, drew harsh comments and stigmatization (Goffman 1963) from non-Indian Canadians, compelled her to change the dietary habits of her family to incorporate more 'Canadian' dishes. Her sartorial choices were also influenced by the practicalities of everyday life and included mostly "western" trousers and blouses. Though she enjoyed dressing up in colorful Indian traditional attire, she reserved those outfits for special, traditional occasions and celebrations.

Finally, clothes formed an important aspect of an attempt to fit-in or belong in both Canada and India. ${ }^{11}$ The professional versus the casual (or traditional) divide was sharper for the older women. For instance, Preeti (56) had this to say:

I love wearing sarees. . . But there is no occasion to wear sarees often here. Plus, the weather ... I wear pants and shirts, tops to work. You want to fit in right, you don't want to stick out. I find it more comfortable to wear it at home. . I wear Punjabi suits and sarees when I go to India.

Similarly, Sangeeta expressed a strong desire to fit in through appropriate dressing:

Occasionally I will dress up. But I am not like I have to look perfect. . . Like you will see my daughter, who is in the journalism. For her, you know, she looks very often in the mirror and "How do I look, my hair and my. .." No, I don't do that, but I do dress up. I wear my outfits for every occasion, whether it is Christmas or Halloween. . . For our Indian occasions I wear nice sarees or Anarkalis or whatever dress, whatever I want to wear, whatever people are wearing there.

Taken together, expressions of identity are situational and contingent upon the shifting notions of home. Fitting-into Canadian society was often achieved by a simultaneous (studied) masking of their ethnic identities. At the same time, demonstrating belonginess in their ethnic community was asserted through everyday practices and rituals such as donning traditional Indian garments and making yearly trips to the country.

\section{Discussion}

Building on the theories of embodiment, we have examined how our respondents described and experienced their transition into old age. In particular, we have analyzed how the meanings they attributed to aging and oldness reflected cultural norms that associated later life with a loss of physical and social vitality. While the participants equated youthful bodies with physical functionality and social worth, they defined old age in terms of physical decline, increasing dependence, and diminished social roles. At the same time, similar to previous studies that have found that growing old entails contradictory emotional reactions to bodily changes and social roles (Bennet et al. 2017; Gilleard and Higgs 2018; Laz 2003; Simpson 2016), many of the participants articulated conflicting feelings about their changing physical and social realities. On the one hand, the participants were accepting of the inevitability of age-related bodily changes and death. On the other hand, they also conveyed annoyance, if not discontent, at their perceived inability to mitigate those changes. Like the older Korean immigrants in United States in Tae-Ock Kauh's (1999) study, our participants too reported feeling both relief as well as a sense of rejection resulting from their altered familial and social roles. These paradoxes were embedded in a culturally contextualized and prescribed performance and construction of gender with associated norms and ideals concerning masculine and feminine bodies, comportment, and social roles. The women in our study interpreted their experience of growing old primarily in terms of bodily 
changes. In contrast, the men tended to emphasize how aging was undermining their economic and social power. While both male and female participants expressed some reluctance to accept these physical and social changes, all the participants had reprioritized the importance of their physical attributes; functionality often trumped appearance in later life(Bennett et al. 2017; Jankowski et al. 2014, Reboussin et al. 2000) body.12

An ambivalent perception of home was observed among the participants in our study. Most participants, though not always consciously, referred to both Canada and India (and often Africa while talking about their childhood), as home. Using Marco Antonsich's (2010) concept of belonging as the description of "the feeling of attachment to a symbolic space of familiarity and 'home.' Lena Nare uses belonging to refer to "the sense of being a part of and 'fitting in' to a particular locale or place, which can refer to a neighbourhood or to a community, or to a wider national entity" $(2017,628)$. Belonging not only is limited to feelings but also translates into ways of living and everyday practices such as food habits and sartorial choices (Bennett 2015; Nare 2017). Although such duality or ambivalence in experiencing belongingness among diasporic younger adults has been well researched, not much has been explored among aging diasporas. What distinguishes the older diaspora in terms of their connection with their homeland is the increased opportunity and enticement for them to visit India post-retirement (especially during winters). These increased proximities to homeland contribute significantly to the reshaping of their later life identities. Unsurprisingly, this push and pull of belonging and nostalgia was less likely to be incumbent on the age of the participants than the type of migration. Irrespective of their age, the participants who had migrated directly from India demonstrated a stronger pull towards their homeland than the twice removed and the second-generation migrants.

We found that most participants experienced a sense of duality in their everyday construction of self. We argue that the sense of selfhood (as seen in studies of Bauman and Raud 2015; Coupland and Gwyn 2003) is intricately related to the embodied experiences of aging among the participants. These embodied experiences, in turn, are contingent upon spaces (homes, culture) and temporality occupied simultaneously by the participants. To be sure, this duality in the embodied experience of aging, expressed by the participants in their ideas about the physical and social markers of age as well as with the fluid idea of home in later life, is reflected in their everyday beliefs and practices. For instance, as noted earlier, the ambivalence between accepting bodily markers of age and a will to resist aging is starkly evident in our study. Coupled with (a reluctant) acceptance of reduced energy, agility, and flexibility as well as the 'slowing down' with advancing age, the participants also demonstrated a firm belief in an ability to delay aging or 'becoming old' (defined often in terms of functional limitations of being able to do everyday chores and activities) by remaining physically active and continuing to do their own work. ${ }^{13}$ Such coexisting contradictions were also evident in the mixed emotions induced by the change in the roles and anticipated status in the family and the society at large. The relief perceived by transferring responsibilities to the younger members was also tainted with the accompanying loss of social worth (in the form of reduced respect and diminished participation in decision-making). These physiological and social changes in later life were accompanied by uncertainties and insecurities and required new coping mechanisms. A similar tension was evident in the participants' appreciation for the Canadian health care system, and, at the same time, the fear of the unavailability of social support for mobilizing health care facilities during a medical emergency.

Finally, coping with the apprehensions of growing old in a cultural context that places huge emphasis on individualism, the idea of aging well becomes automatically linked to a healthy body and (economic) independence. Most of our participants, irrespective of their ages, expressed apprehension about their increasing dependency on adult children due to loss of physical or cognitive functionality. Participants across all age groups, younger old (55 years-70 years), as well as the older old (above 70 years), 
expressed equal concern regarding loss of physical/cognitive functionality and increased dependence with age. Hence, it is not surprising that study participants noted the cultural importance of health management practices, even though they were not actively using such techniques. Apart from the fear of dependence, loneliness in later life emerged as a major concern among those growing old in the diaspora. Along with the physiologically limiting influences of age, the relatively smaller population of diasporic Gujaratis in the study region and the limited social interaction with people from outside the Gujarati community further increased the possibility of alienation and loneliness in later life. To combat loneliness and social isolation, the senior community associated with the Gujarati Society of British Columbia often found ways to get together and celebrate festivals to 'practice' both age and identity. Laz's (2003) contention that age and embodiment are both mutually constituted is illustrative of our participants' negotiations of the dualities of body and the experience and meanings of home.

\section{Limitation}

Certain caveats remain. Due to time constraints associated with the duration of the fellowship, a majority of the participants could not be interviewed multiple times which, we believe could have helped us to offer deeper insights into our participants' perceptions and experiences of identity, integration, and belonging. We were also unable to pay specific attention to the sociological differences in caste identities. While we are acutely aware of the heterogeneity in diets, lifestyles, everyday practices, and belief systems by caste affiliations, a careful investigation of those dimensions remained outside the scope of the current study. Moreover, due to the restricted nature of the sample recruitment (relying on snowball method), all our study participants belonged to the middle class. This limited our ability to examine how age remains interlocked with other forms of social ordering such as social class. Despite these limitations, by focusing on a diasporic community and bringing to the fore the cultural construction of aging bodies and aging self, this study expands the scope of aging research. In the process, we have complicated the notion of "home" among aging immigrants and have broadened the possibility of multi-sited gerontological inquiry around questions of body, embodiment, and everyday subjectivities.

\section{Notes}

1. In her study on older adults living in institutional facilities in Bengal (India), cultural anthropologist Sarah Lamb, highlights that dependence in later life, especially in the form of receiving seva - "respectful service and care, paradigmatically provided by juniors to elders" (Lamb, 2013, 176), is seen as an appropriate normative expectation of the life course.

2. For example, see Tannistha Samanta 2018, for an examination of the sociological possibility of "Third Age" in India; Jagriti Gangopadhyay 2020, for understanding the emergence of new class of older adults who redefine and repurpose aging through sustained financial independence and social interactions.

3. Critical gerontologist, Naomi Woodspring (2016), who has written extensively on Baby Boomers in the developed West, defines 'embodiment' as the "collapse of the mind/body split" and "a profound intertwining of the two" (80). Scholars working on aging have conceptualized embodiment through a range of dimensions including activity, fitness, health, appearance, and illness (See for example Hurd 1999; Laz 2003). We find Laz's conceptualization particularly fruitful for our analysis; Laz privileges the phenomenology of the body and argues how embodiment (just like age) is both accomplished and performed. Drawing from Connell's (1995) powerful analysis of "body-reflexive practices," Laz shows how individuals often through routine or at times by collective and social work, "make" their bodies. Seen this way, embodiment involves social relations and symbolism.

4. For more details on the Gujarati migrants in Canada, see Chundawat 2015; Jha 2010, etc.

5. Based on the time and original place of migration, four types of migrants were identified: 1) the 'twice removed' or 'twice migrated' (Jayaram 2008), comprising of the migrants from East African countries such as 
Fiji, Kenya, Uganda and Tanzania, who came to Canada as political refugees in the 1970s; 2) the first-generation migrants from India who migrated to Canada for education, employment and/or marriage; 3) the later-life migrants or the 'zero-generation' migrants who followed their children who had migrated to Canada; 4) the second-generation migrants who were born in Canada.

6. Mazzarella, William. 2011. The Middle Class. (http://anthropology. uchicago.edu/pdfs/mazz_middleclass.pdf, accessed June 16, 2019).

7. Slyvia Vatuk (1990), based on her long-term study of aging in America and India, analyzes how old age related physical, mental, or financial dependence on others is seen as a source of anxiety depending on larger cultural conditioning. Vatuk points out that anxiety of dependence on others in America is rooted culturally in collating the loss of physical and economic dependence with the loss of self-respect and self-reliance. While intergenerational dependence and reciprocity are culturally sanctioned expectations in the Indian context. Dependence anxiety in the Indian older adults' springs from experiential and realistic concerns about their children failing to uphold their filial duties towards the aging parents.

8. Vaisho Devi is a popular Hindu temple and pilgrimage centre located in the northern most state of Jammu and Kashmir in India.

9. Language did not seem to be a factor in restricting social interaction for most of the participants. Two of the participants, who were zero generation migrants, reported facing difficulty with the language for the first few years after they had moved to Canada. However, they mentioned that they learnt to speak English within the first 2-3 years. Only one of the female participants, a first-generation migrant, faced difficulty and had reservations about communicating in English. $90 \%$ of the participants could communicate in English, though they preferred to use a mix of Hindi, Gujarati, and English languages for the interview sessions.

10. See for example, Lena paNare 2017.

11. See Twigg 2009, for a careful analysis of how clothes are inextricably tied to gender, identity, and embodiment in old age.

12. In her study of Korean older women living in New Zealand, Chung (2018) linked the increasing salience of body functionality in later life to the lack of expectation of informal care (such as familial support) in a transnational context.

13. Everyday work for the participants, often, referred to household chores such as kitchen duties for women and cleaning the house for men. Most of the participants, irrespective of their gender, reported the regular task of picking up their grandchildren (if they lived in the same city) from school and taking care of them till they were collected by their parents later in the evening.

\section{References}

Alcoff, Linda. 1988. "Cultural Feminism Versus Post-Structuralism: The Identity Crisis in Feminist Theory." Signs: Journal of Women in Culture and Society 13 (3): 405-436.

Andersen, Ranberg, K, K Christensen, B Jeune, A Skytthe, L Vasegaard, and Jw Vaupel. 1999. Age and Ageing 28 (4): 373-377.

Antonsich, Marco. 2010. "Searching for Belonging-an Analytical Framework." Geography Compass 4, no. 6: 644-659.

Bartky, Sandra Lee. 2015. Femininity and Domination: Studies in the Phenomenology of Oppression. Routledge.

Bauman, Zygmunt, and Rein Raud. 2015. Practices of Selfhood. John Wiley \& Sons.

Bayer, Kathryn. 2005. "Cosmetic Surgery and Cosmetics: Redefining the Appearance of Age." Generations 29 no. 3 : 13-18.

Bennett, Julia. 2015. "'Snowed in!': Offbeat Rhythms and Belonging as Everyday Practice." Sociology 49 no. 5: $955-$ 969. 
Bennett, Erica V., Laura Hurd Clarke, Kent C. Kowalski, and Peter RE Crocker. 2017. "“I'll do Anything to Maintain my Health": How Women Aged 65-94 Perceive, Experience, and Cope with their Aging Bodies." Body Image 21: 71-80.

Bordo, Susan.1993. Unbearable Weight: Feminism, Western Culture, and the Body. University of California Press.

Braun, Virginia, and Victoria Clarke. 2006. “Using Thematic Analysis in Psychology." Qualitative Research in Psychology 3 (2): 77-101.

Brijnath, Bianca. 2014. Unforgotten: Love and the Culture of Dementia Care in India. Vol. 2. Berghahn Books.

Brooks, Abigail T. 2010. “Aesthetic Anti-Ageing Surgery and Technology: Women's Friend or Foe?” Sociology of Health and Illness 32 (2): 238-57.

Butler, Judith. 1990. Gender Trouble: Feminism and the Subversion of Identity. New York: Routledge.

Butler, Judith. 1993. Bodies that Matter: On the Discursive Limits of Sex. New York: Routledge.

Butler, Judith. 2004. Undoing Gender. New York: Routledge.

Calasanti, Toni M., and Kathleen F. Slevin. 2001. Gender, Social Inequalities and Aging. NY: Alta Mitra Press.

Carter, Claire. 2016. “Still Sucked into the Body Image Thing: The Impact of Anti-Aging and Health Discourses on Women's Gendered Identities." Journal of Gender Studies 25 (2): 200-214.

Chundawat, Virendra Singh. 2015. "Socio-cultural study of Gujarati diaspora with special reference to England, America and Canada." PhD diss.

Clarke, Adele E., Janet K. Shim, Laura Mamo, Jennifer Ruth Fosket, and Jennifer R. Fishman. 2003 “Biomedicalization: Technoscientific Transformations of Health, Illness, and US Biomedicine." American Sociological Review 68 (2): 161-94.

Cohen, Lawrence. 1998. No Aging in India: Modernity, Senility and the Family. UK: Oxford University Press.

Conrad, Peter. 2007. The Medicalization of Society. Baltimore: Johns Hopkins University Press.

Coupland, Justine, and Richard Gwyn (Eds.). 2002. Discourse, the Body, and Identity. New York: Palgrave Macmillan.

Csordas, Thomas J. 1999. “Embodiment and Cultural Phenomenology." In Perspectives on Embodiment: The Intersections of Nature and Culture. Edited by Gail Weiss and Honi Fern Haber. New York. Routledge.

Davey, Judith, and Kathy Glasgow. 2006. “Positive Ageing: A Critical Analysis.” Policy Quarterly 2 (4): 21-27.

De Beauvoir, Simone. 1953. The Second Sex. Translated by Howard Madison Parshley. New York: Vintage Books.

Estes, Carroll L., and Elizabeth A. Binney. 1989. “The Biomedicalization of Aging: Dangers and Dilemmas.” The Gerontologist 29 (5): 587-596.

Featherstone, Mike, and Mike Hepworth. 1991. “The Mask of Ageing and the Postmodern Life Course." In The Body: Social Process and Cultural Theory. Edited by Featherstone, Mike, Mike Hepworth, and Bryan S. Turner, 371-398. Thousand Oaks, CA: Sage.

Featherstone, Mike, and Mike Hepworth. 2005. “Images of Ageing: Cultural Representations of Later Life” In Cambridge Handbook of Age and Ageing. Edited by Johnson, Malcolm L., Vern L. Bengtson, Peter G. Coleman, and Thomas BL Kirkwood. Cambridge: Cambridge University Press, pp. 354-62.

Fernandes, Leela. 2006. India's New Middle Class: Democratic Politics in an Era of Economic Reform. University of Minnesota Press.

Foucault, Michel. 1973. Madness and Civilization: A History of Insanity in the Age of Reason. Translated by Richard Howard. New York: Vintage.

Foucault, Michel. 1975. The Birth of the Clinic: An Archeology of Medical Perception. Translated by Alan M. Sheridan Smith. New York: Vintage. 
Foucault, Michel. 1979. Discipline and Punish: The Birth of the Prison. Translated by Alan M. Sheridan Smith. New York: Vintage.

Foucault, Michel. 1991. “Governmentality.” Translated by Rosi Braidotti and revised by Colin Gordon. In The Foucault Effect: Studies in Governmentality. Edited by Graham Burchell, Colin Gordon and Peter Miller, 87-104. Chicago, IL: University of Chicago Press.

Fraser, Suzanne. 2003. Cosmetic Surgery, Gender and Culture. New York: Palgrave MacMillan.

Furman, Frida Kerner. 1997. Facing the Mirror: Older Women and Beauty Shop Culture. New York: Routledge

Gagné, Patricia, and Deanna McGaughey. 2002. “Designing Hegemony and the Exercise of Power among Women who have Mammoplasty." Gender and Society (16) 6: 814-38

Gangopadhyay, Jagriti. 2020. "Examining the Changing Processes of Aging in Urban Kolkata." Ageing International 45, no. 3: 273-287.

Gergen, Kenneth J. 1985. "Social Constructionist Inquiry: Context and Implications." In The Social Construction of the Person. Edited by Kenneth J. Gergen and Keith E. Davis, 3-18. New York: Springer-Verlag.

Greenhalgh, Susan. 2015. Fat-talk Nation. Ithaca, NY: Cornell University Press.

Gilleard, Chris, and Paul Higgs. 2005. Contexts of Ageing: Class, Cohort and Community. Cambridge, UK: Polity.

Gilleard, Chris, and Paul Higgs. 2018. “Unacknowledged Distinctions: Corporeality Versus Embodiment in Later Life." Journal of Aging Studies 45: 5-10.

Goffman, Erving. 1963. Stigma. Hammondsworth. UK: Penguin.

Gullette, Margaret Morganroth. 1997. Declining to Decline: Cultural Combat and the Politics of Midlife. University of Virginia Press.

Hockey, Jenny, and Allison James. 2004. “How do we Know That we are Aging? Embodiment, Agency and Later Life." In Old Age and Agency, edited by Emmanuelle Tulle, 157-172. New York: Nova Science Publishers.

Holstein, Martha B. 2006. “On Being an Aging Woman.” In Age Matter Realigning: A Feminist Thinking. Edited by Tony M. Calasanti and Kathleen F. Slevin, 313-334. Routledge.

Heywood, Leslie, and Jennifer Drake, eds. 1997. Third Wave Agenda: Being Feminist, Doing Feminism. Minneapolis, MN: University of Minnesota Press.

Hood, Bruce. 2012. The Self Illusion: Who do You Think You Are? London: Constable and Robinson

Hurd Clarke, Laura. 2002a. “Beauty in Later Life: Older Women's Perceptions of Physical Attractiveness." Canadian Journal on Aging 21 (3): 429-42.

-----.2002b. “Older Women's Perceptions of Ideal Body Weights: The Tensions Between Health and Appearance Motivations for Weight Loss." Ageing and Society 22 (6): 751-73.

Hurd Clarke, Laura. and Alexandra Korotchenko. 2010. “Shades of Grey: To Dye or Not to Dye One's Hair in Later Life." Ageing and Society 30 (6): 1011-26.

Jayaram, Narayana. 2008. “Heterogeneous Diaspora and Asymmetrical Orientations: India, Indians and the Indian Diaspora." Diaspora Studies 1 (2): 1-21.

Jha, Nalini Kant. 2010. “The Indian Community in Canada.” Diaspora Studies 3 (1): 41-55.

Jenkins, Richard. 2010. Social Identity. 3rd ed. London: Routledge.

Katz, Stephen. 1996. Disciplining Old Age: The Formation of Gerontological Knowledge. Charlottesville, Virginia: University Press of Virginia.

Kauh, Tae-Ock. 1999. "Changing Status and Roles of Older Korean Immigrants in the United States". The International Journal of Aging and Human Development 49 (3): 213-229. 
Lamb, Sarah. 2000. White Saris and Sweet Mangoes: Aging, Gender, and Body in North India. University of California Press.

Lamb, Sarah. 2002a. Love and Aging in Bengali Families. Everyday life in South Asia 56-68.

-----2002b. "Intimacy in a Transnational Era: The Remaking of Aging Among Indian Americans". Diaspora: A Journal of Transnational Studies 11 (3): 299-330.

Lamb, Sarah. 2013. Personhood, Appropriate Dependence and Rise of Elder Care Institutions in India. In Transitions and Transformations: Cultural Perspectives on Aging and The Life Course, edited by Lynch, Caitrin, and Jason Danely. Berghahn Books.

Lamb, Sarah. 2014. "Permanent Personhood or Meaningful Decline? Toward a Critical Anthropology of Successful Aging." Journal of Aging Studies 29, 41-52.

Lamb, Sarah, Jessica Robbins-Ruszkowski, Anna Corwin, Toni Calasanti, and Neal King. 2017. Successful Aging as a Contemporary Obsession: Global Perspectives. Rutgers University Press.

Laz, Cheryl. 2003. “Age Embodied.” Journal of Aging Studies 17 (4): 503-519.

Lowe, Lisa. 2005. “Heterogeneity, Hybridity, Multiplicity: Marking Asian American Differences.” A Companion to Asian American Studies 254-275.

Moody, Harry R., and Sanjay Sood. 2010. “Age Branding,” In The Aging Consumer: Perspectives from Psychology and Economics. Edited by Drolet, Aimee, and Carolyn Yoon, 229-245. New York: Routledge.

Moore, Sarah EH. 2008. “Gender and the New Paradigm of Health.” Sociology Compass 2: 268-280

Näre, Lena. 2017 "Identity and Ambivalence in Everyday Transnationalism: Older-Aged Gujaratis in London." Identities 24: 5 625-640.

Rowe, John W., and Robert L. Kahn. 1987. “Human Aging: Usual and Successful.” Science 237: 143-149.

Rutagumirwa, Sylivia Karen, and Ajay Bailey. 2017. "I Have to Listen to This Old Body": Femininity and the Aging Body." The Gerontologist 59 (2): 368-377

Samanta, Tannistha. 2018. “The 'Good Life': Third Age, Brand Modi and the Cultural Demise of Old Age in Urban India." Anthropology \& Aging 39 (1): 94-104.

Slevin, K. F. 2006. “The Embodied Experiences of Old Lesbians.” In Age Matters: Realigning Feminist Thinking. Edited by T.M. Calasanti \& K. F. S Levin, 247-68. NY, New York: Routledge.

Slevin, K.2008. “Disciplining Bodies: The Aging Experiences of Older Heterosexual and Gay Men.” Generations 32 (1): 36-42.

Slevin, K. F. 2010. "If I had Lots of Money...I'd Have a Body Makeover': Managing the Aging Body." Social Forces 88 (3): 1003-1020.

Slevin, Kathleen F. and Christine E. Mowery. 2012. “Exploring Embodied Aging and Ageism among Old Lesbians and Gay Men." In Sex for life: From Virginity to Viagra, How Sexuality Changes Throughout our Lives. Edited by Carpenter, Laura, and John DeLamater, 260-277. NYU Press.

Simpson, Paul. 2016. “The Resources of Ageing? Middle-aged Gay Men's Accounts of Manchester's Gay Voluntary Organizations." The Sociological Review 64 (2): 366-383.

Smirnova, Michelle Hannah. 2012, “A Will to Youth: The Woman's Anti-Aging Elixir.” Social Science E Medicine 75 (7): 1236-43.

Sontag, Susan. 1972. “The Double Standard of Aging." Saturday Review of the Society 1 (1): 29-38.

Terry, Gareth, Nikki Hayfield, Victoria Clarke, and Virginia Braun. 2017. “Thematic Analysis.” The Sage Handbook of Qualitative Research in Psychology 17-37.

Turner, Bryan S. 1995. Medical Power and Social Knowledge. Sage. 
Twigg, Julia. 2004. "The Body, Gender and Age: Feminist Insights in Social Gerontology." Journal of Aging Studies 18 (1): 59-73.

Twigg, Julia 2009. “Clothing, Identity and Embodiment of Age." In Aging and Identity: A Postmodern Dialogue. Edited by Powell, Jason, and Tony Gilbert. New York: Nov Science Publishers.

Twigg, Julia., and Wendy Martin. 2015. The Routledge Handbook of Cultural Gerontology. London: Routledge.

Twigg, Julia. 2018. "Fashion, the Media and Age: How Women's Magazines use Fashion to Negotiate Age Identities." European Journal of Cultural Studies: 21 (3): 334-348.

Vatuk, Sylvia. 1990. “To be a Burden on Others." Divine Passions: The Social Construction of Emotions in India 64-91.

Wolf, Naomi. 1991. The Beauty Myth. New York: Anchor.

Wong, Sabrina T., Grace J. Yoo, and Anita L. Stewart. 2006. “The Changing Meaning of Family Support among Older Chinese and Korean Immigrants." Journal of Gerontology: Social Sciences 61B: S4-S9.

Woodspring, Naomi. 2016. Baby Boomers: Time and Ageing Bodies. Bristol: Policy Press. 